\title{
Role of pressure in stabilization of oxynitride phosphor synthesis
}

\author{
Barbara J. Adamczyk ${ }^{1} \cdot$ Dirk Poelman $^{2} \cdot$ Katleen Korthout $^{2} \cdot$ Daniel Michalik $^{1} \cdot$ Tomasz Pawlik $^{1} \oplus$. \\ Małgorzata Sopicka-Lizer ${ }^{1}$
}

Received: 4 January 2021 / Accepted: 13 May 2021 / Published online: 8 June 2021

(c) The Author(s) 2021

\begin{abstract}
The possibilities of improving the crystallization and optical properties of strontium europium oxonitridosilicate phosphor powders were discussed. Two different routes of synthesis were presented: traditional solid-state reaction method and gas pressure synthesis. It was proven that altering the partial pressure during the process of synthesis enhances crystallization of a desired single, triclinic $\mathrm{SrSi}_{2} \mathrm{O}_{2} \mathrm{~N}_{2}$ phase. XANES measurements confirmed complete reduction of the trivalent europium activator ions in all of the tested materials. The photoluminescent properties were determined by emission, excitation and decay times measurements. CIE1931 colour points and luminous efficacy were calculated as well. Thermal quenching studies in the range of $0-225{ }^{\circ} \mathrm{C}$ confirmed good thermal stability of the investigated powders combined with excellent quantum efficiency at room temperature.
\end{abstract}

Keywords LED · Oxynitride phosphor · Photoluminescence $\cdot$ Synthesis $\cdot$ Solid state reaction · Extended X-ray absorption structure (EXAFS · XANES)

\section{Introduction}

Solid state lighting, as an alternative for incandescent and fluorescent lamps, has received increasing interest for many years, due to energy savings, long life and durability of the devices and great quality of the obtained light. The 2014 Nobel Prize for S. Nakamura, I. Akasaki and H. Amano for the invention of InGaN-based high brightness doubleheterostructure blue LEDs stressed the significance of the research in the area of materials for white LEDs and the importance of white LEDs for society.

Nowadays, one of the most widely used activator ions for phosphors for white LED's excited by blue/UV radiation is $\mathrm{Eu}^{2+}$ due to its $4 \mathrm{f}-5 \mathrm{~d}$ transition which ensures both wide emission and excitation bands, strongly depending on the local environment. In the last two years, publications on various hosts for $\mathrm{Eu}^{2+}$ ions were reported [1-7], shifting the emission maxima from blue to red. Despite this fact, the

Tomasz Pawlik

tomasz.pawlik@polsl.pl

1 Faculty of Materials Engineering, Silesian University of Technology, Krasińskiego 8, 40-019 Katowice, Poland

2 LumiLab, Department of Solid State Sciences, Ghent University, Krijgslaan 281-S1, 9000 Gent, Belgium well-known europium-doped $\mathrm{SrSi}_{2} \mathrm{O}_{2} \mathrm{~N}_{2}$ oxynitride phosphor still attracts significant attention, as one of the most suitable green phosphors for white LEDs, characterized by high quantum efficiency, chemical stability, high colour purity, limited thermal quenching and a broad excitation band [8-11]. However, it seems that further research on this compound is necessary, especially on the crystal structure and synthesis methods. A triclinic crystal structure of this compound isotypic to $\mathrm{EuSi}_{2} \mathrm{O}_{2} \mathrm{~N}_{2}$ was reported by Seibald et al. and Oeckler et al. $[10,12]$. This oxynitride is characterized by a low symmetry layered structure, as a result of three-fold bridging $\mathrm{N}^{3-}$ ions [10]. The compound can crystallize in the monoclinic system also, as Seibald et al. reported before [13]. This is why any modification of chemical composition or change of synthesis method/ parameters can bring many difficulties.

The $\mathrm{SrSi}_{2} \mathrm{O}_{2} \mathrm{~N}_{2}$ phosphor is usually obtained via a traditional, one-step solid-state reaction method presented in many publications [14-18] or via a two-step method [19, 20] including preparation of a strontium silicate precursor. Various $\mathrm{Eu}^{2+}$ concentrations and different synthesis parameters complicate the comparison of presented results. Nonetheless, comparing phosphors doped with $2 \mathrm{~mol} \%$ of activator ions obtained at $1400{ }^{\circ} \mathrm{C}[8], 1450{ }^{\circ} \mathrm{C}[14]$ and $1500{ }^{\circ} \mathrm{C}$ [21] via the one-step method reveals that despite relatively 
small changes of synthesis parameters, diffuse reflection spectra can exhibit 1 or 2 minima, suggesting different absorption of the host lattice. The excitation and emission spectra are changing as well, especially the range and shape of excitation and FWHM of emission spectra. Another synthesis approach is a two-step solid-state reaction method, which is supposed to provide a greater control over ongoing reactions during synthesis. Zhang et al. [22] obtained $\mathrm{Sr}_{0,98} \mathrm{Eu}_{0,02} \mathrm{Si}_{2} \mathrm{O}_{2} \mathrm{~N}_{2}$ phosphor by synthesis of $\mathrm{Sr}_{2} \mathrm{SiO}_{2}: \mathrm{Eu}^{3+}$ precursor with $\mathrm{Si}_{3} \mathrm{~N}_{4}$ at $1450{ }^{\circ} \mathrm{C}$. As the authors presented, a single triclinic oxynitride phase was obtained when a 1.1-1.5 ratio of $\mathrm{Si}_{3} \mathrm{~N}_{4} / \mathrm{Sr}_{2} \mathrm{SiO}_{4}$ was used. In the materials discussed above $[8,21]$ next to the P1 space group structure, an additional unknown phase was visible in XRD patterns. Fang et al. [23], who conducted the same type of synthesis, proved that $\mathrm{Sr}_{0,98} \mathrm{Eu}_{0,02} \mathrm{Si}_{2} \mathrm{O}_{2} \mathrm{~N}_{2}$ phosphor obtained via a two-step synthesis was characterized by enhanced emission intensity and higher thermal stability in comparison to material obtained from a one-step process.

From these various results, it is clear that it is necessary to find better and more reproducible synthesis methods and conditions for these oxynitrides. One of the main drawbacks of the solid-state reaction method in a powder bed is the necessity of applying a flow of reducing/forming gas (nitrogen/hydrogen) during synthesis. This crucial factor enhances reduction of europium ions into a desired $\mathrm{Eu}^{2+}$ oxidation state and it controls the nitrogen partial pressure throughout the synthesis of oxynitride. Accordingly, a gas flow over the powder bed constantly removes gaseous reaction products. Thus, it results in a simultaneous change of the partial pressure of involved reactive gases what makes the solidstate method an even more unstable process. This is why a high gas pressure synthesis in a closed reactor appears as a promising replacement for conventional methods of obtaining oxynitride phosphors.

In the present study, $\mathrm{Sr}_{0.96} \mathrm{Eu}_{0.04} \mathrm{Si}_{2} \mathrm{O}_{2} \mathrm{~N}_{2}$ materials synthesized by 2 pathways are compared: via a traditional one-step solid-state reaction method in $\mathrm{N}_{2} / \mathrm{CO}$ flow and via gas pressure synthesis at $6 \mathrm{MPa}$. Application of a high gas pressure during synthesis can improve not only the stability of the process, but also prevents evaporation of $\mathrm{Si}_{(\mathrm{g})} / \mathrm{SiO}_{(\mathrm{g})}$, resulting in a stoichiometry of the final powders much closer to the designed one. The influence of these factors on structural and optical properties of oxynitride phosphors is, certainly, not without significance. Following the work of McMillan [24], high pressure during synthesis can influence coordination numbers, valence states and therefore also optical properties such as increased absorption of material. To the best of our knowledge, there is no available research on the influence of such high gas pressure on the crystallization and optical properties of oxynitride phosphors. In addition, X-ray absorption near-edge spectroscopy (XANES) and extended $\mathrm{X}$-ray absorption fine structure (EXAFS) were performed in order to describe the local environment of activator ions and their oxidation state in the oxynitride structure, to clear the role of the essential factors to obtain pure green emission.

\section{Materials and methods}

$\mathrm{Sr}_{0.96} \mathrm{Eu}_{0.04} \mathrm{Si}_{2} \mathrm{O}_{2} \mathrm{~N}_{2}$ phosphors were obtained with raw materials $\mathrm{SrCO}_{3}$ (Alfa Aesar, 99\%), $\mathrm{Eu}_{2} \mathrm{O}_{3}$ (Treibacher, 99.99\%), $\mathrm{Si}_{3} \mathrm{~N}_{4}$ (Sigma Aldrich, 98\%) and $\mathrm{SiO}_{2}$ (Merck 99\%). The molar fraction of silicon in $\mathrm{SiO}_{2}$ in comparison with $\mathrm{Si}_{3} \mathrm{~N}_{4}$ was slightly lower $(0.2 / 1.8)$ than the stoichiometric one $(0.5 / 1.5)$ in order to compensate oxygen contamination in the used silicon nitride powder. All investigated samples were homogenized via high energy ball milling (Fritsch Pulverisette 7; 500 rpm; 1 h; B/P ratio 4:1). In all cases, a one-step synthesis was applied. The sample obtained via the solid-state reaction (SSR) method was synthesized in $\mathrm{N}_{2}(99.99 \%)$ flow in a graphite furnace (Thermal Technology) at $1450{ }^{\circ} \mathrm{C}$ during $4 \mathrm{~h}$. A $\mathrm{N}_{2}$ flow was applied throughout the process; thus gaseous products of the reaction were removed. Since the phosphor was synthesised via traditional way it will be concerned as a reference material for presented studies. Material prepared by gas pressure synthesis (GPS) was obtained in a graphite furnace (HIP AIP8-30HPED, American Isostatic Presses) under a nitrogen pressure of $6 \mathrm{MPa}$ in a closed reactor, at $1600{ }^{\circ} \mathrm{C}$ during $2 \mathrm{~h}$. In this method, the $\mathrm{CO}_{(\mathrm{g})}$, formed as a result of carbonates decomposition, was not removed during synthesis. Powder X-ray diffraction (XRD) patterns were measured with $1 \%$ min rate and $0.02^{\circ}$ step on a Siemens D5000 diffractometer $(40 \mathrm{kV}$, $40 \mathrm{~mA}$ ) using $\mathrm{Cu} \mathrm{K} \alpha 1$ radiation $(\lambda=0.154 \mathrm{~nm})$. The morphology and microstructure were observed in a scanning electron microscope (SEM; Hitachi S-3400 N) operating at $20 \mathrm{kV}$. Particle size distribution (PSD) measurements were performed on a Malvern Mastersizer3000 analyzer after 1 min. of ultrasonic treatment, assuming a refraction index $n=1.75$. Reflection spectra were recorded using a Varian Cary $500 \mathrm{UV}-$ Vis spectrometer equipped with an integrating sphere, in the $250-800 \mathrm{~nm}$ range. $\mathrm{BaSO}_{4}$ powder was used as a reference. Emission and excitation spectra were recorded with an Edinburgh Instruments FS920 spectrometer, using a $450 \mathrm{~W}$ Xe arc lamp as the excitation source. Emitting colour, CIE 1931 chromaticity as well as luminous efficacy of investigated powders were calculated using the LED ColorCalculator software by Osram Sylvania [25]. Quantum efficiency (QE) measurements were performed using an integrating sphere coupled to an EMCCD camera (Princeton Instruments ProEM 16,002), attached to a spectrograph (Princeton Instruments Acton SP2358), using $\mathrm{Al}_{2} \mathrm{O}_{3}$ powder as a reference. Thermal quenching (TQ) measurements in the range $0-225{ }^{\circ} \mathrm{C}$ were performed using the same detection system. 
In order to study the oxidation state and local environment of Eu activator ions in the crystal structure, X-ray absorption near-edge spectroscopy (XANES) and extended X-ray absorption spectroscopy (EXAFS) measurements were performed. These measurements were carried out at the Dutch Belgian beam line (DUBBLE, BM26A) of the $6 \mathrm{GeV}$ European Synchrotron Radiation Facility (ESRF) in Grenoble, France, operating with a 160-200-mA electron current [26]. The synchrotron radiation was monochromated with a double $\mathrm{Si}(111)$ monochromator, suppressing the higher harmonics. EuS and $\mathrm{Eu}_{2} \mathrm{O}_{3}$ were used as energy reference materials. Eu $\mathrm{L}_{\mathrm{III}}$-edge XANES and EXAFS spectra were recorded with an energy step of typically $1 \mathrm{eV}$. Spectra for the reference materials were collected in transmission mode using ion chambers. The XANES and EXAFS spectra of the phosphor powders were collected in fluorescence mode by monitoring the Eu L $\alpha 1$ peak fluorescence line (centred around $5.85 \mathrm{keV}$ ). The phosphors could not be measured in transmission mode because of the low dopant concentration and the relatively strong X-ray absorption of the host matrix. The X-ray fluorescence yield was detected with a nine element monolithic Ge detector [27]. Determination of the edge position, background subtraction, and normalization of the calibrated raw X-ray absorption data was performed using Athena [28].

\section{Results}

Figure 1 presents a comparison of the XRD patterns of the synthesized materials. It can be seen that the SSR material diffraction peaks, as well as those of the sample obtained by the GPS method, are consistent with the pattern of the $\mathrm{SrSi}_{2} \mathrm{O}_{2} \mathrm{~N}_{2}$ triclinic phase (ICDD\# 01-076-3141). The relative intensities of some diffraction peaks are lower (e.g. $010 ; 110$ or -110 ) or higher (e.g. 022 and $0-22$ or 042 and
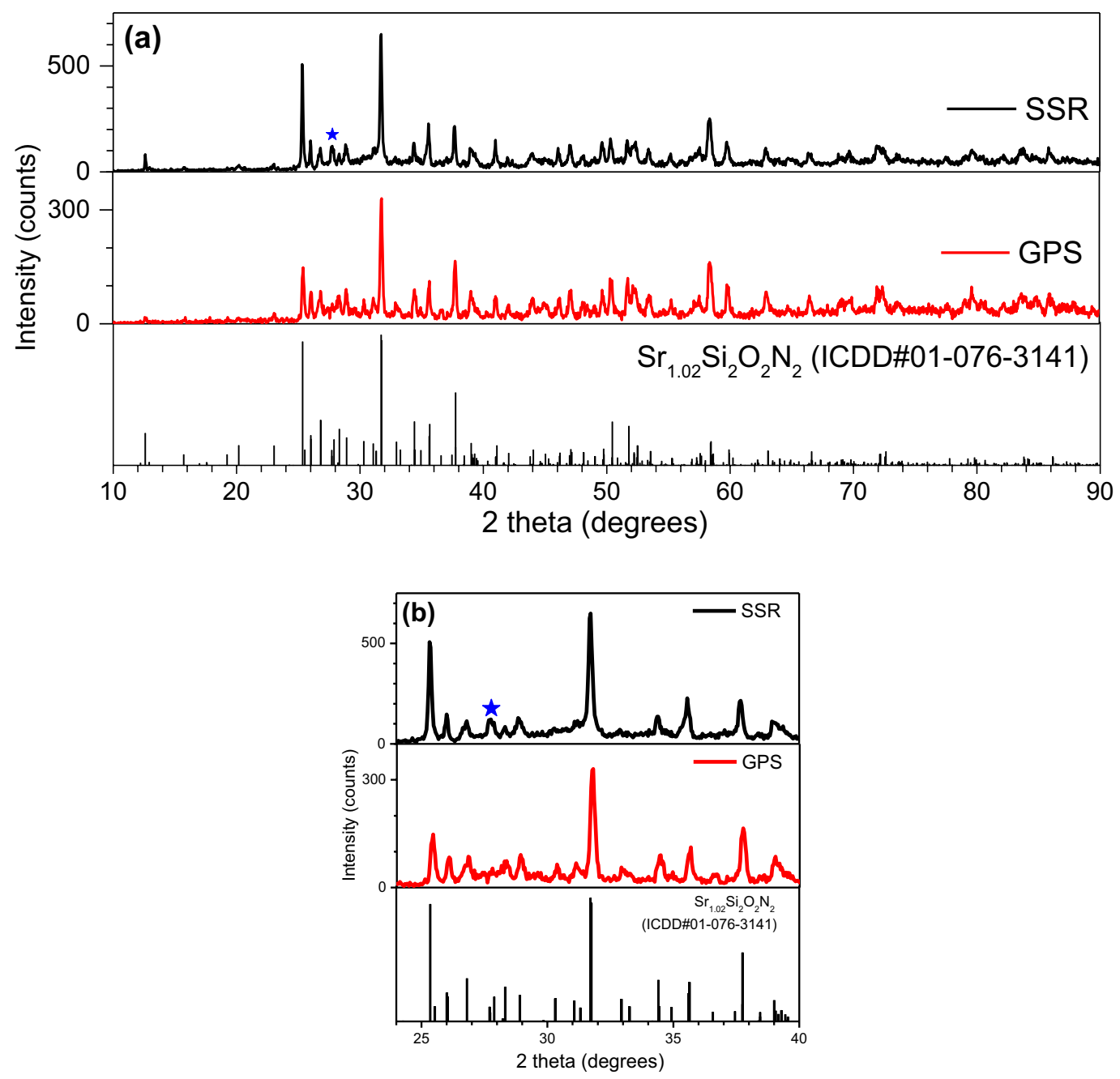

Fig. 1 XRD patterns of $\mathrm{Sr}_{0.96} \mathrm{Eu}_{0.04} \mathrm{Si}_{2} \mathrm{O}_{2} \mathrm{~N}_{2}$ phosphor obtained by solid-state reaction (SSR) and gas pressure synthesis (GPS): a full range of diagrams; b 24-40 $2 \Theta^{\circ}$ range 
Table 1 Comparison of FWHM values of the two strongest XRD peaks

\begin{tabular}{lll}
\hline & FWHM $(2 \theta)$ \\
\hline Sample \# & $(020) \sim 25.4^{\circ}$ & $(220) ;(\overline{2} 10) \sim 31.5^{\circ}$ \\
SSR & 0.14 & 0.19 \\
GPS & 0.21 & 0.21 \\
\hline
\end{tabular}
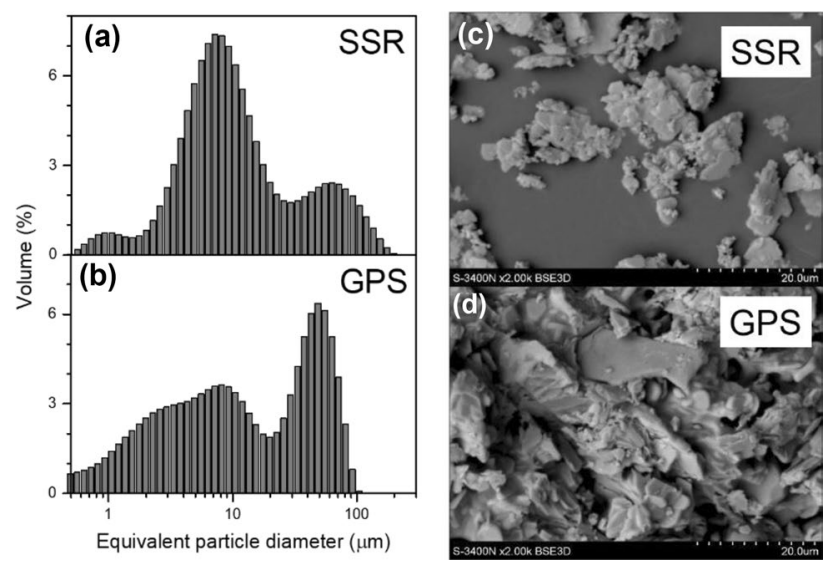

Fig. 2 SEM photographs and particle size distribution of studied materials

$0-42$ ) if compared to the standard pattern of triclinic polymorph. The intensity variation could be ascribed to several real crystal structure imperfections as twinning. Formation of twin domains which involves overlapping reflections in this polymorph was reported earlier [12, 20, 29]. Interestingly there are subtle differences in the phase composition between both compared samples, since additional peaks at $30.5 ; 31.2 ; 36.5 ; 37 ; 51.3 ; 56^{\circ}$ and diffuse scattering are visible in the SSR specimen though noteworthy broadening of the peaks has been observed in the GPS one (Table 1). Observed deviations of diffraction patterns in a reference sample could originate from the stacking disorder and/or intergrowth in this layered triclinic oxonitridosilicate since they causes significant alterations in the X-ray diffraction pattern, concerning both line positions and widths. The mentioned deviations are slightly higher in the reference sample than in the GPS one. In summary of the XRD studies, it seems that applying GPS method led to manufacturing the monophase triclinic $\mathrm{SrSi}_{2} \mathrm{O}_{2} \mathrm{~N}_{2}: \mathrm{Eu}^{2+}$ powder, as the SSR specimen was contaminated by an additional phase (marked in the diagram by the star).

SEM images and PSD graphs are presented in Fig. 2. The SSR sample is characterized by flakey particles with an average particle size of approx. $8 \mu \mathrm{m}$. Powders obtained via high pressure synthesis are characterized by flakey particles also; however, they are assembled into larger agglomerates with diameter up to $60 \mu \mathrm{m}$. The reason of the enhanced particles growth is the intensified matter transport via diffusion during synthesis, as a result of 60 times higher nitrogen pressure and subsequent enhanced sintering.

The application of two synthesis methods: solid-state reaction or gas pressure synthesis led to formation of different final $\mathrm{SrSi}_{2} \mathrm{O}_{2} \mathrm{~N}_{2}: \mathrm{Eu}^{2+}$ phosphor powders. Their diversity is visible in the phase composition, crystallite and particle size and resultant luminescence properties. First of all, solid-state synthesis with a significant amount of a covalent powder of $\alpha-\mathrm{Si}_{3} \mathrm{~N}_{4}$ is a complex process related to the low coefficient of diffusion and high equilibrium partial pressure of $\mathrm{Si}_{(\mathrm{g})} / \mathrm{SiO}_{(\mathrm{g})}$ as a result of $\mathrm{Si}_{3} \mathrm{~N}_{4}$ decomposition at elevated temperature in reducing atmosphere of a graphite furnace. Application of nitrogen high pressure prevents decomposition of $\mathrm{Si}_{3} \mathrm{~N}_{4}$ and losses of volatiles in the final product; thus the monophase triclinic $\mathrm{SrSi}_{2} \mathrm{O}_{2} \mathrm{~N}_{2}$ could be obtained as it happened in the GPS sample. At the same time, nitrogen high pressure limited the crystal growth of the triclinic phase since broadening of XRD peaks was considerable, but it enhanced sintering of phosphor particles as the distribution of particles sizes shows (Fig. 2). The latter process could be explained by the rules of the first stage of sintering/densification. The pressure-assisted sintering occurs via particles sliding and rearrangement, while grain growth of the new phase is facilitated by atomic diffusion and/or by evaporation and condensation processes. It seems that both liquidfree syntheses, i.e. GPS and SSR, channel to the similar distorted crystal structure of the triclinic polymorph. The presence of the unknown phase in the SSR sample could be assigned to some material losses and the consequent deviation of $\mathrm{SrSi}_{2} \mathrm{O}_{2} \mathrm{~N}_{2}$ stoichiometry in both cations and anions ratio. Moreover, low FWHM values of the relevant diffraction peaks (Table 1) correspond to larger crystallites in SSR samples; thus nucleation of triclinic phase was somehow restricted.

Table 2 presents a summary of the measured optical properties. The reference sample is characterized by strong absorption in the blue range with maximum at $417 \mathrm{~nm}$, which could be ascribed to $4 \mathrm{f}^{7} \rightarrow 4 \mathrm{f}^{6} 5 \mathrm{~d}^{1}$ transition in $\mathrm{Eu}^{2+}$ ions. Synthesis via the GPS method leads to a shift of the maximum absorption toward longer wavelengths. It was also possible to notice a difference in the absorption range from 250 to $300 \mathrm{~nm}$ (not shown here) attributed to the absorption of the host [8]. The latter is related to the electron excitation from valence to conduction band and it could be affected by the details of the host crystal structure.

The sample obtained via gas pressure synthesis showed emission spectra (Fig. 3) characteristic for $\mathrm{Eu}^{2+}$ ions in a $\mathrm{SrSi}_{2} \mathrm{O}_{2} \mathrm{~N}_{2}$ crystal lattice-a single emission peak with maximum position at $\lambda_{\mathrm{em}}=535 \mathrm{~nm}$, which can be ascribed to the $4 \mathrm{f}^{6} 5 \mathrm{~d}^{1} \rightarrow 4 \mathrm{f}^{7}$ transition in $\mathrm{Eu}^{2+}$ ions, corresponding to saturated green emission. It is good to point out that the 
Table 2 Optical properties of materials obtained via different methods synthesis method

\begin{tabular}{lll}
\hline Sample \# & SSR & GPS \\
\hline Body colour & Orange & Dark green \\
Max. absorption $(\mathrm{nm})$ & 418 & 431 \\
Excitation range $(\mathrm{nm})$ & $240-506$ & $234-510$ \\
Excitation max $(\mathrm{nm})$ & 370 & 370 \\
Emission max $(\mathrm{nm})$ & 536 & 535 \\
iQE $(\%)$ & 62 & 61 \\
eQE $(\%)$ & 54 & 61 \\
Luminous efficacy $(\mathrm{lm} / \mathrm{W})$ & 486 & 520 \\
Decay time, $\tau_{1}(\mu \mathrm{s})$ & 0.401 & 0.594 \\
Decay time, $\tau_{2}(\mu \mathrm{s})$ & 1.006 & 1.1 \\
\hline
\end{tabular}

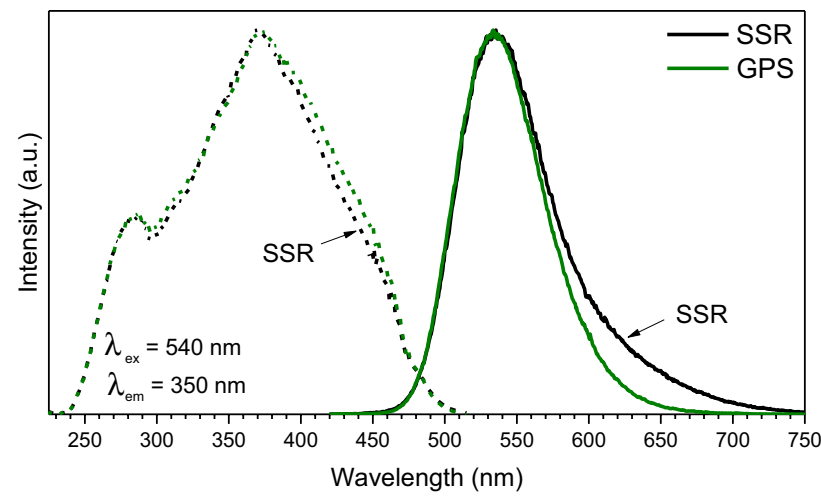

Fig. 3 PL and PLE spectra of phosphors obtained via SSR or GPS method

emission spectrum of the SSR sample consists of an additional band, located at $\sim 620 \mathrm{~nm}$, which strongly affects the colour coordinates and decreases the colour purity (Fig. 4). Earlier works on $\mathrm{SrSi}_{2} \mathrm{O}_{2} \mathrm{~N}_{2}:{ }_{0.02} \mathrm{Eu}^{2+}$ phosphors obtained via the solid-state reaction method reported also broadening of emission spectra in the form of an additional shoulder in the range of 400-500 $\mathrm{nm}$ (Song et al. [8]) or on the red side. Bachman et al. [30] explained a pronounced shoulder on the low energy side of the spectrum as originating from traces of $\mathrm{Sr}_{2} \mathrm{Si}_{5} \mathrm{~N}_{8}: \mathrm{Eu}^{2+}$. According to Liu et al. [31], emission spectra of this oxygen free phase cover the 540-800 $\mathrm{nm}$ range with maximum position at $625 \mathrm{~nm}$, when the material is synthesized at $1450{ }^{\circ} \mathrm{C}$. In this cited paper, the additional nitride phase was not recognized in XRD patterns; however, the lower sensitivity of this method has to be taken into account. According to Liu et al., both $\mathrm{SrSi}_{2} \mathrm{O}_{2} \mathrm{~N}_{2}$ and $\mathrm{Sr}_{2} \mathrm{Si}_{5} \mathrm{~N}_{8}$ phases crystallize at the same temperature $-1200{ }^{\circ} \mathrm{C}$; however, the $\mathrm{Sr}_{2} \mathrm{Si}_{5} \mathrm{~N}_{8}$ phase could be detected by XRD only if a higher synthesis temperature was applied.

Fitting the emission spectra of the reference specimen with the symmetric Gaussian line shape were performed

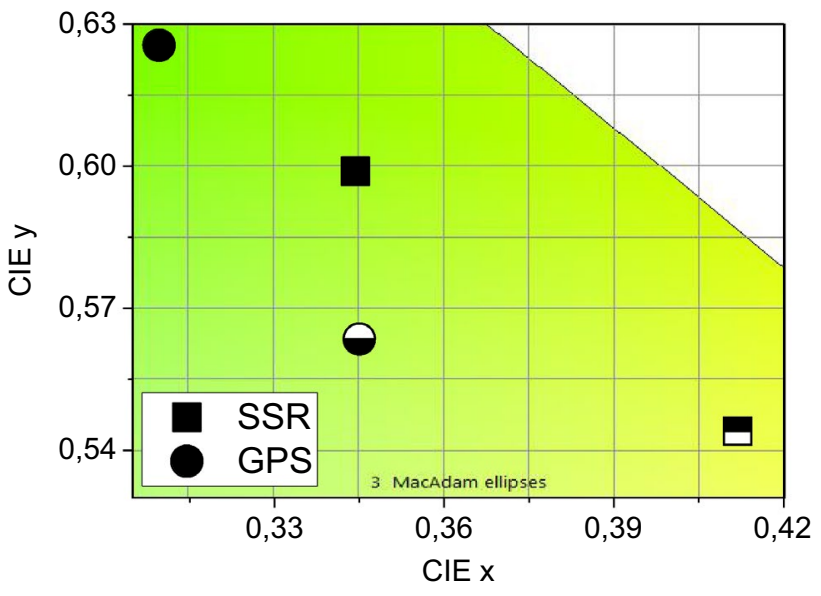

Fig. 4 CIE1931 colour coordinates at room temperature (fully filled markers) and at $225{ }^{\circ} \mathrm{C}$ (half full markers) of phosphors obtained via SSR or GPS method

for emission spectrum converted to energy scale. A second emission maximum at about $576 \mathrm{~nm}$ was revealed, which is too low to be ascribed to the $\mathrm{Sr}_{2} \mathrm{Si}_{5} \mathrm{~N}_{8}$ phase but close to $\mathrm{Sr}_{3} \mathrm{SiO}_{5}: \mathrm{Eu}^{2+}$ with reported emission maximum at $566 \mathrm{~nm}$ under $395 \mathrm{~nm}$ excitation [32]. Presence of this strontiumrich silicate could imply some $\mathrm{Si}$ losses before $\mathrm{SrSi}_{2} \mathrm{O}_{2} \mathrm{~N}_{2}$ synthesis started.

As mentioned above, solid-state synthesis of $\mathrm{SrSi}_{2} \mathrm{O}_{2} \mathrm{~N}_{2}$ carried out in reducing atmosphere with simultaneous gas flow increases the probability of silica reduction. For this reason, features like synthesis temperature, reduction atmosphere and silicon mono-oxide partial pressure $\left(\mathrm{SiO}_{(\mathrm{g})}\right)$ should be considered. During the solid-state reaction, both silica sources $\left(\mathrm{Si}_{3} \mathrm{~N}_{4}\right.$ and $\left.\mathrm{SiO}_{2}\right)$ are continuously reduced in $\mathrm{CO}$ atmosphere at high temperature according to reaction (1)

$2 \mathrm{SrCO}_{3}+\mathrm{Si}_{3} \mathrm{~N}_{4}+\mathrm{SiO}_{2}=2 \mathrm{SrSi}_{2} \mathrm{O}_{2} \mathrm{~N}_{2}+2 \mathrm{CO}_{2(\mathrm{~g})}$

However, the side reaction could also occur at higher temperature:

$\mathrm{Si}_{3} \mathrm{~N}_{4}+\mathrm{SiO}_{2}+2 \mathrm{CO}_{2(\mathrm{~g})}=4 \mathrm{SiO}_{(\mathrm{g})}+2 \mathrm{CO}_{(\mathrm{g})}+2 \mathrm{~N}_{2(\mathrm{~g})}$

Reaction (2) is controlled by partial pressure of the reactive gases: $\mathrm{SiO}_{(\mathrm{g})}, \mathrm{CO}_{(\mathrm{g})}, \mathrm{N}_{2(\mathrm{~g})}$ accomplishment of $\left(\mathrm{SiO}_{(\mathrm{g})}\right)$ partial pressure equilibrium point at given temperature would terminate the decomposition of solids, however applying the continuous gas flow makes it more complex. It clearly shows that oxygen and/or nitrogen losses from solids could be observed as well. Consequently, the presence of strontium and oxygen richer $\mathrm{Sr}_{3} \mathrm{SiO}_{5}$ is possible.

In case of gas pressure synthesis conducted in a closed reactor chamber, the reducing atmosphere is obtained by $\mathrm{SrCO}_{3}$ decomposition, leading to $\mathrm{CO} / \mathrm{CO}_{2}$ presence. What follows, partial pressure of $\mathrm{CO}_{(\mathrm{g})}$ and $\mathrm{SiO}_{(\mathrm{g})}$ depends only 
on applied nitrogen pressure. As a result, the high partial pressure of nitrogen moves reaction (2) to the left side which limits an amount of silicon monoxide volatilization. This is why application of high pressure during synthesis resulted in elimination of the red part of the spectra in comparison with the sample obtained by solid-state reaction. Based on the presented considerations, we could conclude that higher phase purity with designed stoichiometry of this phosphor has been accomplished during gas pressure synthesis.

External (eQE) and internal (iQE) quantum efficiency (Table 2) of the SSR sample is approx. 55 and 60\%, respectively. The external quantum efficiency is lower, since then, not all of the incident photons are taken into account. Gas pressure synthesis leads to equalization of $\mathrm{iQE}$ and $\mathrm{eQE}$ values, corresponding to an almost $100 \%$ absorption of the incident light. The dark green colour of the GPS powder might suggest lower quantum efficiency in comparison with the bright SSR material. On the contrary, the eQE is higher, presumably due to an increased absorption efficiency of the powders obtained in high pressure environment. Lower than expected quantum efficiency of GPS specimens could be ascribed to residual carbon precipitates (dark green colour) because of high partial pressure of $\mathrm{CO}$ in the closed reactor. One notes very high quantum yield of $\mathrm{SrSi}_{2} \mathrm{O}_{2} \mathrm{~N}_{2}: \mathrm{Eu}^{2+}$ reported lately for the phosphor manufactured directly from $\mathrm{SrO}$ without carbon oxides presence [33]. Luminous efficacy, calculated from obtained emission spectra, is higher for GPS sample as well $(520 \mathrm{~lm} / \mathrm{W})$, due to pure green colour of the sample. Lower luminous efficacy determined for the SSR sample $(486 \mathrm{~lm} / \mathrm{W})$ was a results of a 'tail' in the emission spectrum in the deep red, where the eye sensitivity is low (see Fig. 3).

Thermal quenching of investigated samples (Fig. 5) performed in $0-225^{\circ} \mathrm{C}$ range confirmed that emission intensity of the samples is reduced less than $50 \%$ at $225^{\circ}$. The SSR was expected to have lower thermal stability in comparison with the second sample, due to phase impurity issues causing internal stresses of crystal lattice and increased amount of defects. Indeed, higher temperature stability was observed in sample obtained via gas pressure synthesis method. The emission intensity decreased by only $39 \%$ at $225{ }^{\circ} \mathrm{C}$ for this sample, which is an excellent value in view of possible application as LED phosphor, where LED chip temperatures typically rise up to $150{ }^{\circ} \mathrm{C}$. Despite the fact that the sample obtained via GPS is thermally more stable than SSR material ( $43 \%$ decrease of intensity), the results are quite similar. For both materials, there is no significant change of the colour point at high temperatures (Fig. 4). The slight change of thermal quenching in both tested specimens occurs at about $100{ }^{\circ} \mathrm{C}$ and could be ascribed to $\mathrm{Sr}_{3} \mathrm{SiO}_{5}:$ Eu presence in SSR phosphor since the abrupt decrease in $\mathrm{Eu}^{2+}$ emission intensity over $100{ }^{\circ} \mathrm{C}$ was reported earlier [34].

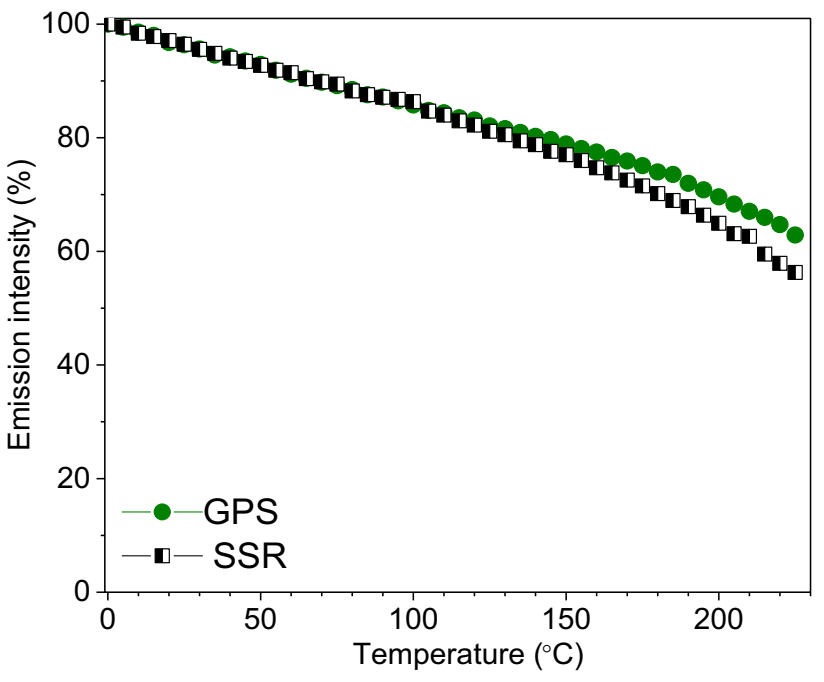

Fig. 5 Temperature dependence of PL intensity of materials obtained via SSR and GPS

The shape of the fluorescent decay curves of the GPS obtained specimen indicates a bi-exponential behaviour, as expected from the relatively high amount of activator ions.

(4 mol\%). Calculated values of both decay components are presented in Table 2. Sample obtained by GPS shows lifetimes of approx. $0.6 \mu \mathrm{s}$ for the first exponential and approx. $1.1 \mu \mathrm{s}$ for the second exponential, higher than that of the SSR phosphor, and corresponding with a lower nonradiative decay rate. All presented results show that applying high pressure in a synthesis is the optimum way to obtain highly efficient green oxynitride phosphor powders.

Proper reduction of the oxidation state of the activator ions is one of the crucial factors to obtain desirable optical properties of Eu-doped phosphors, as shown by Xie et al. [35]. XANES measurements were performed for both studied phosphors. It is good to point out that almost complete reduction of $\mathrm{Eu}^{3+}$ ions was achieved (Fig. 6) for the materials, which is quite unusual for oxynitride phosphors in general, making broadening the knowledge on synthesis methods/parameters even more desirable. The results show that the $2+$ oxidation state of Eu was obtained using both synthesis methods and the high amount of $\mathrm{Eu}^{2+}$ could be related rather to the synthesis in a reducing atmosphere of $\mathrm{CO} / \mathrm{N}_{2}$ rather than to gas pressure. Despite similar results obtained for both studied materials, the GPS sample exhibits the most efficient reduction of $\mathrm{Eu}^{3+}$ ions. Those results are consistent with higher eQE and improved thermal stability in comparison to the SSR material.

Incorporation of the Eu ions in host lattice was studied as well using EXAFS. The Eu ion is able to build in 8 different $\mathrm{Sr}$ sites [12] which are coordinated by $6 \mathrm{O}$ atoms and $1 \mathrm{~N}$ atom, with a preferential substitution on the standard sites ( $\mathrm{Sr} 1, \mathrm{Sr} 2, \mathrm{Sr} 3$ and $\mathrm{Sr} 4)$. A detailed EXAFS 


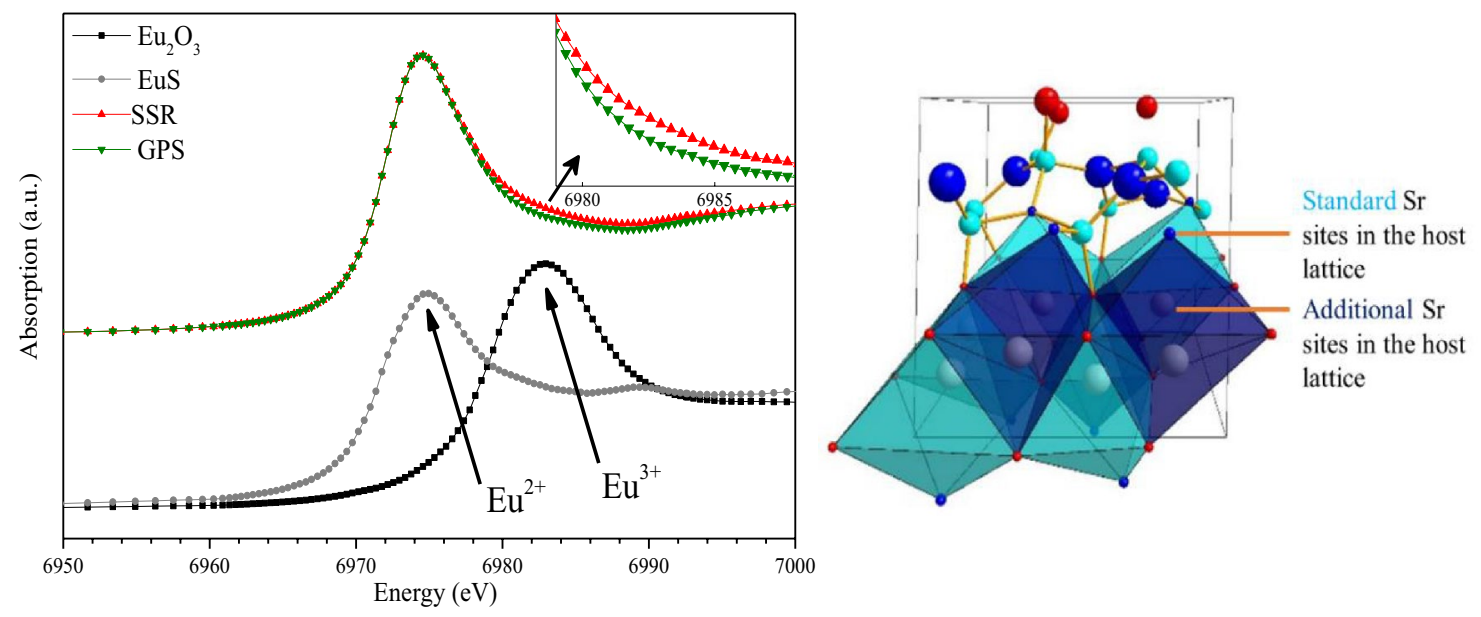

Fig. 6 XANES spectra of reference materials $\mathrm{EuS}$ (for the $\mathrm{Eu}^{2+}$ oxidation state), $\mathrm{Eu}_{2} \mathrm{O}_{3}$ (for the $\mathrm{Eu}^{3+}$ oxidation state) and samples coming from solid-state reaction (SSR) and gas pressure synthesis (GPS)

analysis (not shown) was performed using multiple data sets fitting on all three samples. For all spectra, a Hanning window was used (k-range: $2.4 \AA^{-1}, 7.9 \AA^{-1}$ ], and $R$-range: [1 $\AA$, $4.3 \AA$ ]). The triclinic crystal structure of $\mathrm{SrSi}_{2} \mathrm{O}_{2} \mathrm{~N}_{2}$ was used to generate the scattering paths for $\mathrm{X}$-rays being absorbed by Eu ions on the standard $\mathrm{Sr}$ sites of the lattice. This analysis showed that the investigated samples are characterized by preferential occupation of the $\mathrm{Sr} 2$ site (approximately $60 \%$ of the Eu ions). The rest of the Eu ions occupy the Sr4 site in the crystal matrix. This effect can be explained by the similar distances $(\mathrm{Eu}-\mathrm{O})$ in the $\operatorname{Sr} 2(2.5889 \AA)$ and $\operatorname{Sr} 4$ sites $(2.6709 \AA)$, compared to the (Eu-O) distance in $\mathrm{EuO}(2.5710 \AA)$ according to PDF database patterns (\# 00-015-0886; \#00-006-0520). This distribution of $\mathrm{Eu}^{2+}$ ions over two separate $\mathrm{Sr}$ sites is compatible with the occurrence of bi-exponential decay curves as presented above.

\section{Conclusions}

In this work, $\mathrm{Sr}_{0.96} \mathrm{Eu}_{0.04} \mathrm{Si}_{2} \mathrm{O}_{2} \mathrm{~N}_{2}$ phosphors were successfully synthesized via the one-step gas pressure or solid-state synthesis. All studied oxynitride phosphors are characterized by the triclinic $\mathrm{SrSi}_{2} \mathrm{O}_{2} \mathrm{~N}_{2}$ phase and show emission band with maximum at $536 \mathrm{~nm}$. XANES measurement confirmed for the first time, complete reduction of the trivalent activator ions in all of the materials. In addition, it has been shown using EXAFS that $\mathrm{Eu}^{2+}$ ions occupy two sites in crystal lattice- $\mathrm{Sr} 2$ and $\mathrm{Sr} 4$ site. Never reported before, this direct comparison of phosphors obtained by solid-state reaction and gas pressure synthesis methods enables to deduce the following:
- It has been proven that applying high pressure during the synthesis was effective in formation of triclinic $\mathrm{SrSi}_{2} \mathrm{O}_{2} \mathrm{~N}_{2}$ phase powder phosphor and elimination of phase contamination, what proves that applying high pressure during synthesis provides better control over $\mathrm{Si}: \mathrm{Sr}$ and O:N ratio as well as reduction of activator ions, opening possibilities for more reproducible optical properties. Due to the more efficient reduction of the europium activator to $\mathrm{Eu}^{2+}$ and improved crystallization of the oxynitrides phase, the material is characterized by enhanced optical properties in comparison with material resulting from the traditional solid-state reaction method.

- The material from gas pressure synthesis is characterized by the most efficient reduction of activator ions. This results in the best thermal stability and luminous efficacy among studied materials, suggesting a more rigid crystal lattice of materials obtained via gas pressure synthesis method.

Acknowledgements The authors would like to acknowledge Dipanjan Banerjee and the rest of the staff at DUBBLE for experimental support and useful discussions.

Funding This work was supported by the National Centre for Research and Development, Warsaw, Poland [Grant Number PBS3/A5/48/2015].

Data availability The raw/processed data required to reproduce these findings cannot be shared at this time as the data also forms part of an ongoing study.

\section{Declarations}

Conflict of interest The authors have no conflict of interest to declare that are relevant to the content of this article. 
Open Access This article is licensed under a Creative Commons Attribution 4.0 International License, which permits use, sharing, adaptation, distribution and reproduction in any medium or format, as long as you give appropriate credit to the original author(s) and the source, provide a link to the Creative Commons licence, and indicate if changes were made. The images or other third party material in this article are included in the article's Creative Commons licence, unless indicated otherwise in a credit line to the material. If material is not included in the article's Creative Commons licence and your intended use is not permitted by statutory regulation or exceeds the permitted use, you will need to obtain permission directly from the copyright holder. To view a copy of this licence, visit http://creativecommons.org/licenses/by/4.0/.

\section{References}

1. X. Zhang, J. Su, X. Yan, Y. Liao, Z. Wu, C. Zhou, Solid State Sci. (2020). https://doi.org/10.1016/j.solidstatesciences.2019.106050

2. X. Zhang, J.-F. Sun, J. Alloys Compd. (2020). https://doi.org/10. 1016/j.jallcom.2020.155225

3. K. Song, H. Yu, Q. Nie, Y. Bai, Y. Guan, J. Yu, L. Guo, J. Lumin 224, 117317 (2020). https://doi.org/10.1016/j.jlumin.2020.117317

4. H. Zhang, D. Yuan, X. Mi, X. Zhang, Z. Bai, X. Liu, J. Lin, J. Alloys Compd. 798, 119-128 (2019). https://doi.org/10.1016/j. jallcom.2019.05.178

5. M.-K. Jang, Y.-S. Cho, Y.-D. Huh, J. Alloys Compd. 828, 154424 (2020). https://doi.org/10.1016/j.jallcom.2020.154424

6. S. Li, S. Qi, K. Liu, H. Yuan, X. Sun, Ceram. Int. 45, 2096720971 (2019). https://doi.org/10.1016/j.ceramint.2019.06.226

7. Q. Wei, J. Ding, X. Zhou, X. Wang, Y. Wang, J. Alloys Compd. 817, 152762 (2020). https://doi.org/10.1016/j.jallcom.2019. 152762

8. X. Song, R. Fu, S. Agathopoulos, H. He, X. Zhao, J. Zeng, Mater. Sci. Eng. B Solid-State Mater. Adv. Technol. 164, 12-15 (2009). https://doi.org/10.1016/j.mseb.2009.06.005

9. R. Mueller-Mach, G. Mueller, M.R. Krames, H.A. Höppe, F. Stadler, W. Schnick, T. Juestel, P. Schmidt, Phys. Status Solidi 202, 1727-1732 (2005). https://doi.org/10.1002/pssa.200520045

10. M. Seibald, T. Rosenthal, O. Oeckler, W. Schnick, Crit. Rev. Solid State Mater. Sci. 39, 215-229 (2014). https://doi.org/10.1080/ 10408436.2013.863175

11. B. Adamczyk, T. Jüstel, J. Plewa, M. Sopicka-Lizer, D. Michalik, Ceram. Int. (2017). https://doi.org/10.1016/j.ceramint.2017. 06.104

12. O. Oeckler, F. Stadler, T. Rosenthal, W. Schnick, Solid State Sci. 9, 205-212 (2007). https://doi.org/10.1016/j.solidstatesciences. 2006.11.009

13. M. Seibald, T. Rosenthal, O. Oeckler, C. Maak, A. Tücks, P.J. Schmidt, D. Wiechert, W. Schnick, Chem. Mater. 25, 1852-1857 (2013). https://doi.org/10.1021/cm400461v

14. Y.H. Song, W.J. Park, D.H. Yoon, J. Phys. Chem. Solids 71, $473-$ 475 (2010). https://doi.org/10.1016/j.jpcs.2009.12.014

15. Q.N. Fei, Y.H. Liu, T.C. Gu, D.J. Wang, J. Lumin 131, 960-964 (2011). https://doi.org/10.1016/j.jlumin.2011.01.001

16. O. Ermakova, W. Paszkowicz, A. Kaminska, J. Barzowska, K. Szczodrowski, M. Grinberg, R. Minikayev, M. Nowakowska,
S. Carlson, G. Li, R. Liu, A. Suchocki, J. Chem. Phys. (2014). https://doi.org/10.1063/1.4883502

17. X. Song, R. Fu, S. Agathopoulos, H. He, X. Zhao, R. Li, J. Electrochem. Soc. 157, J34 (2010). https://doi.org/10.1149/1.3270491

18. L. Liu, R.J. Xie, C. Zhang, N. Hirosaki, Materials 6, 2862-2872 (2013). https://doi.org/10.3390/ma6072862

19. H. Li, H. Chen, L. Yang, M. Guo, J. Lumin 194, 661-666 (2018). https://doi.org/10.1016/j.jlumin.2017.08.065

20. X. Li, R. Zhang, R. Cui, C. Deng, J. Alloys Compd. 650, 470-474 (2015). https://doi.org/10.1016/j.jallcom.2015.07.266

21. X. Song, H. He, R. Fu, D. Wang, X. Zhao, Z. Pan, J. Phys. D. Appl. Phys. 42, 065409 (2009). https://doi.org/10.1088/00223727/42/6/065409

22. H. Zhang, Z. Cheng, Y. Zhang, Z. Hu, J. Yu, N. Zou, J. Mater. Sci. 52, 7605-7614 (2017). https://doi.org/10.1007/ s10853-017-0992-y

23. Y.-C. Fang, P.-C. Kao, Y.-C. Yang, S.-Y. Chu, J. Electrochem. Soc. 158, J246 (2011). https://doi.org/10.1149/1.3600349

24. P.F. McMillan, Curr. Opin. Solid State Mater. Sci. 4, 171-178 (1999). https://doi.org/10.1016/S1359-0286(99)00013-3

25. Color Calculator, Osram Sylvania, 1.7.18, (n.d.)

26. S. Nikitenko, A.M. Beale, A.M.J. van der Eerden, S.D.M. Jacques, O. Leynaud, M.G. O'Brien, D. Detollenaere, R. Kaptein, B.M. Weckhuysen, W. Bras, J. Synchrotron Radiat. 15, 632-640 (2008). https://doi.org/10.1107/S0909049508023327

27. G. Derbyshire, K.C. Cheung, P. Sangsingkeow, S.S. Hasnain, J. Synchrotron Radiat. 6, 62-63 (1999). https://doi.org/10.1107/ S0909049598017695

28. B. Ravel, M. Newville, J. Synchrotron Radiat. 12, 537-541 (2005). https://doi.org/10.1107/S0909049505012719

29. F. Stadler, O. Oeckler, H.A. Hoppe, M.H. Moller, R. Pottgen, B.D. Mosel, P. Schmidt, V. Duppel, A. Simon, W. Schnick, Chem. A Eur. J. 12, 6984-6990 (2006). https://doi.org/10.1002/chem.20060 0409

30. V. Bachmann, C. Ronda, O. Oeckler, W. Schnick, A. Meijerink, Chem. Mater. 21, 316-325 (2009). https://doi.org/10.1021/cm802 394w

31. C. Liu, B. Zhang, L. Hao, X. Xu, J. Rare Earths. 32, 691-695 (2014). https://doi.org/10.1016/S1002-0721(14)60127-7

32. H.K. Yang, H.M. Noh, B.K. Moon, J.H. Jeong, S.S. Yi, Ceram. Int. 40, 12503-12508 (2014). https://doi.org/10.1016/j.ceramint. 2014.04.105

33. L. Chen, Z. Cheng, G. Zheng, G. Yao, L. He, L. Wang, J. Liu, H. Zheng, S. Wei, H. Ni, J. Lumin 230, 117729 (2021). https://doi. org/10.1016/j.jlumin.2020.117729

34. Q. Shao, H. Lin, Y. Dong, Y. Fu, C. Liang, J. He, J. Jiang, J. Sol. State Chem. 225, $72-77$ (2015). https://doi.org/10.1016/j.jssc. 2014.12.005

35. R.J. Xie, H.T. Hintzen, J. Am. Ceram. Soc. 96, 665-687 (2013). https://doi.org/10.1111/jace.12197

Publisher's Note Springer Nature remains neutral with regard to jurisdictional claims in published maps and institutional affiliations. 